\title{
Central Corneal Thickness and its Association with Ocular Parameters
}

Authors:

An-Fei $\mathrm{Li}^{1,2}$

Mei-Ju Chen ${ }^{1,2}$

\section{Affiliations:}

1 Department of Ophthalmology, Taipei Veterans General Hospital

2 National Yang-Ming University, School of Medicine

Financial support and commercial relationships: none

\section{Correspondence to:}

Dr. Mei-Ju Chen

Department of Ophthalmology, Taipei Veterans General Hospital, 201, Section 2, Shih-Pai Road, Taipei 112, Taiwan, R.O.C.

Tel: +886-2-2875-7325

Fax: +886-2-2875-7133

E-mail: mj_chen@vghtpe.gov.tw

\section{Abstract}

Central corneal thickness (CCT) is an important indicator of cornea health. CCT is helpful to ensure sufficient corneal thickness for laser ablation on the era of laser refractive surgery. There has been increased interest in CCT because of its influence on intraocular pressure (IOP) measurement. CCT can affect the accuracy of IOP measurement for the diagnosis and management of glaucoma. Glaucoma is a progressive optic neuropathy with irreversible visual field change. Risk factors include age, race, high IOP and myopia. Myopic eyes are characterized with greater refractive error, flatter corneal curvature and longer axial length. Controversy remains regarding whether the impact of CCT on glaucoma is due to its effects on IOP measurement, or may be due to its associated biomechanical and structural changes. Here, we will review the relationship between CCT and ocular parameters such as refractive error, corneal curvature and axial length.

Key Words: axial length, central corneal thickness, corneal curvature, glaucoma, myopia, refractive error 


\section{Introduction}

Central corneal thickness (CCT) is a valuable indicator of cornea status and is useful for the diagnosis and management of several corneal diseases, including corneal edema caused by different endothelial disorders and contact lens wearing (Rio-Cristobal et al. 2014). For eyes undergoing laser refractive surgery, CCT is helpful to ensure sufficient corneal thickness for laser ablation and to determine minimum stroma beneath the flap to prevent corneal ectasia (Chakrabarti et al. 2001).

It is essential to measure CCT when evaluating patients of glaucoma suspect. Glaucoma is a progressive optic neuropathy with a risk factor for high intraocular pressure (IOP). CCT has long been known to affect the accuracy of IOP measurement. Previous studies have shown a positive correlation between CCT and IOP measured by applanation, which causes overestimation of true IOP in thicker corneas and the converse in thinner ones (Damji et al. 2003). A difference of the $10 \%$ on the CCT could result in a $3.4 \pm 0.9 \mathrm{mmHg}$ variation in IOP measurement (Doughty et al. 2000). It has been demonstrated that CCT is greater in patients with ocular hypertension compared to general population (Singh et al. 2001). A thin CCT is a risk factor for glaucoma (Gordon et al. 2002, Wang et al. 2014) and has been identified as a predictor of glaucoma progression (Leske et al. 2007, Miglior et al. 2007).

In addition, myopic eyes are associated with increased risk for glaucoma (Mitchell et al. 1999). Eyes with more myopic refractive error tend to have greater axial lengths and flatter corneal curvatures (Goss et al. 1997, Chen et al. 2009). The eyeball elongates (Lin et al. 1999) with scleral thinning (Funata \& Tokoro 1990) in the development of myopia. However, there is no general consensus with respect to how CCT varies with axial length, 
refractive error and corneal curvature.

Therefore, we aim to review the relationship between $\mathrm{CCT}$ and other associated ocular parameters.

\section{CCT Measurements}

Ultrasound pachymetry is the most common method to evaluate CCT (Figure 1).

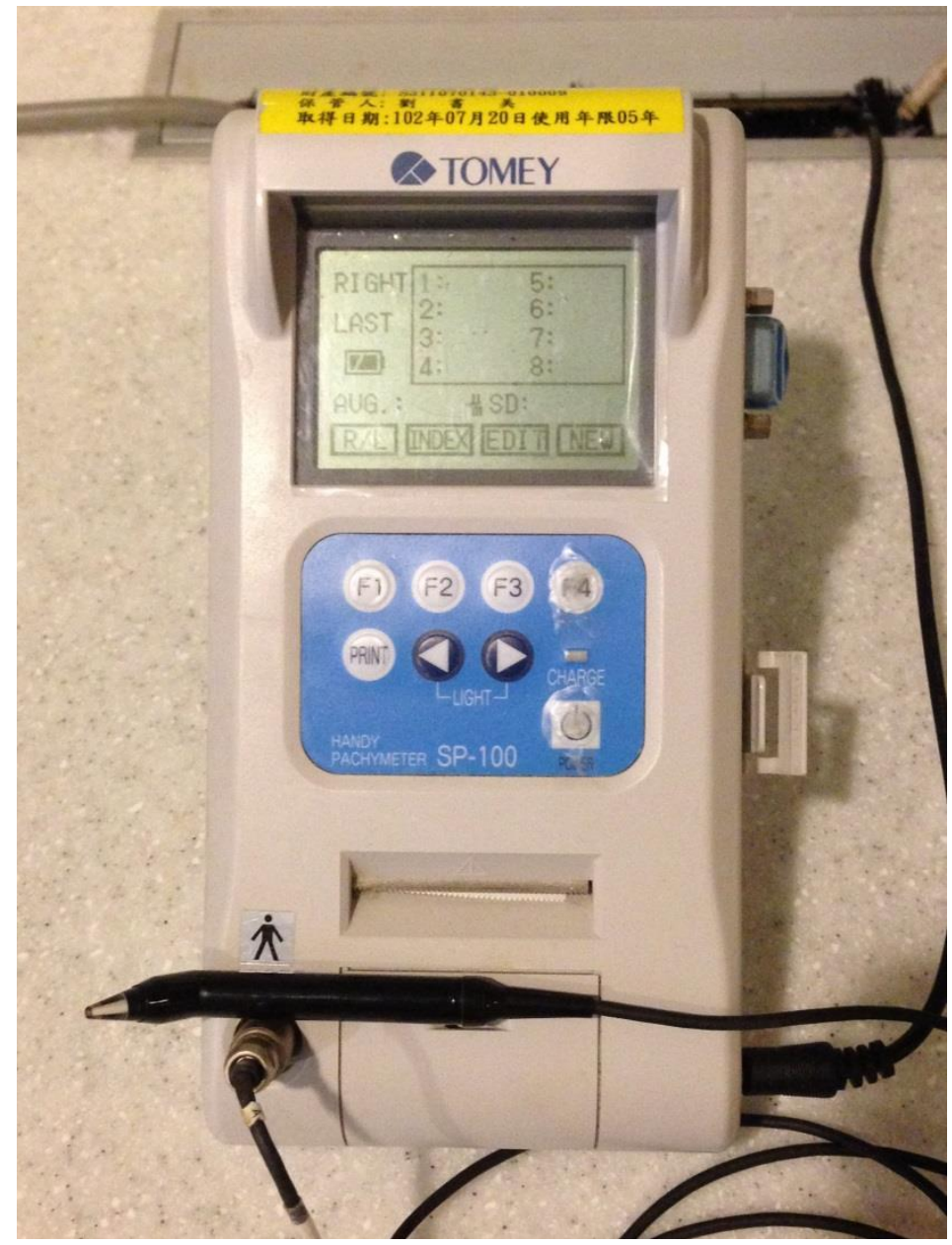

Figure 1. Ultrasound pachymeter

The advantages consist of ease of use, reliability and reasonable cost. When performing this technique, patients need to receive topical anesthesia because of the direct contact of the probe with the cornea. To place the ultrasound probe perpendicular to the cornea may also cause difficult repeatability. Several newer technologies have demonstrated better repeatability and reproducibility; including optical coherence tomography (Martin et al. 2007) (Figure 2), scanning slit topography (Martin et al. 2009) (Figure 3), rotating Scheimpflug camera (Bourges et al. 2009) and Scheimpflug imaging system (Oliveira et al. 2011). 
Medical Research Archives, Vol. 5, Issue 1, January 2017

Central Corneal Thickness and its Association with Ocular Parameters

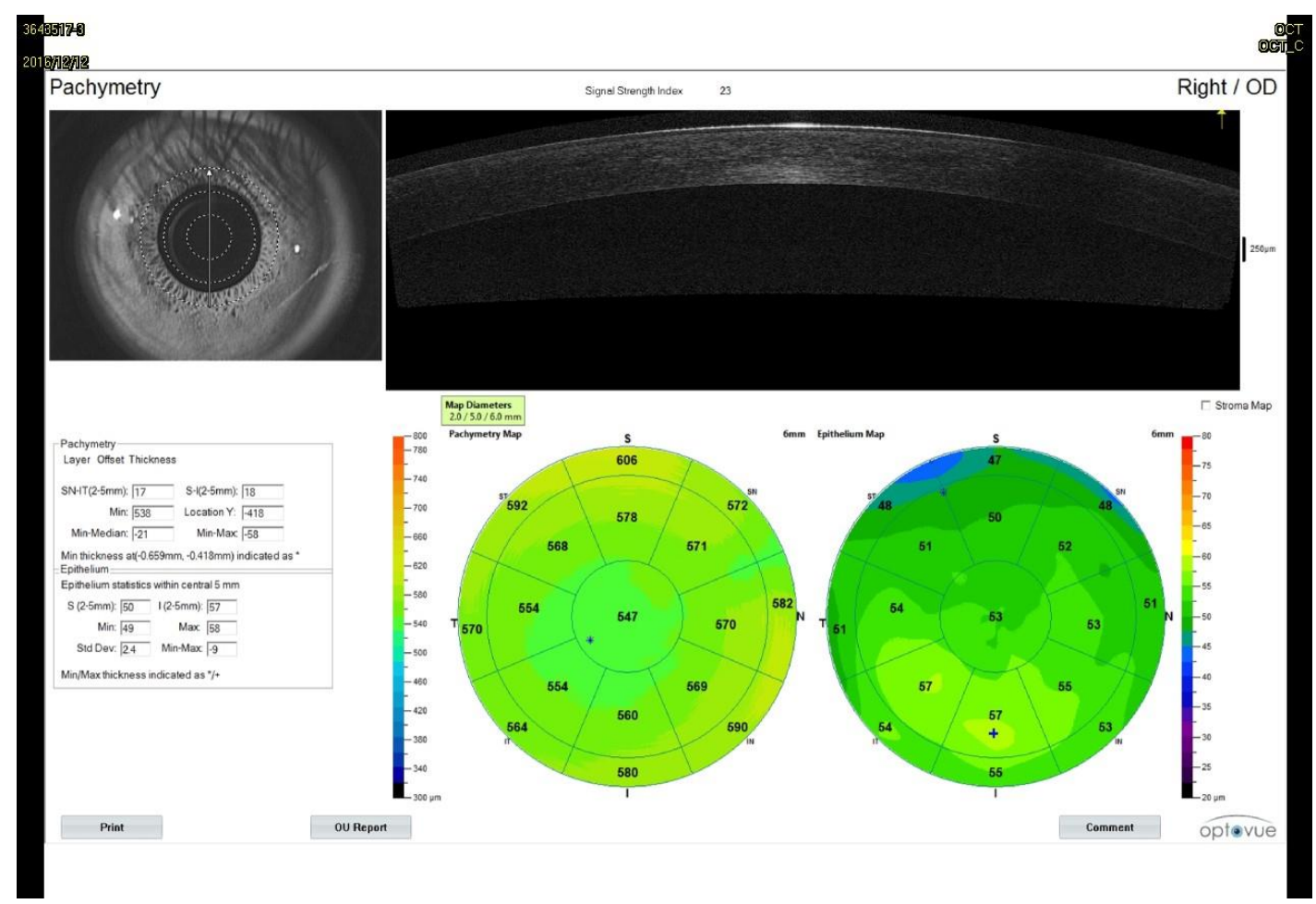

Figure 2. Printout of CCT measurement by anterior segment optical coherence tomography

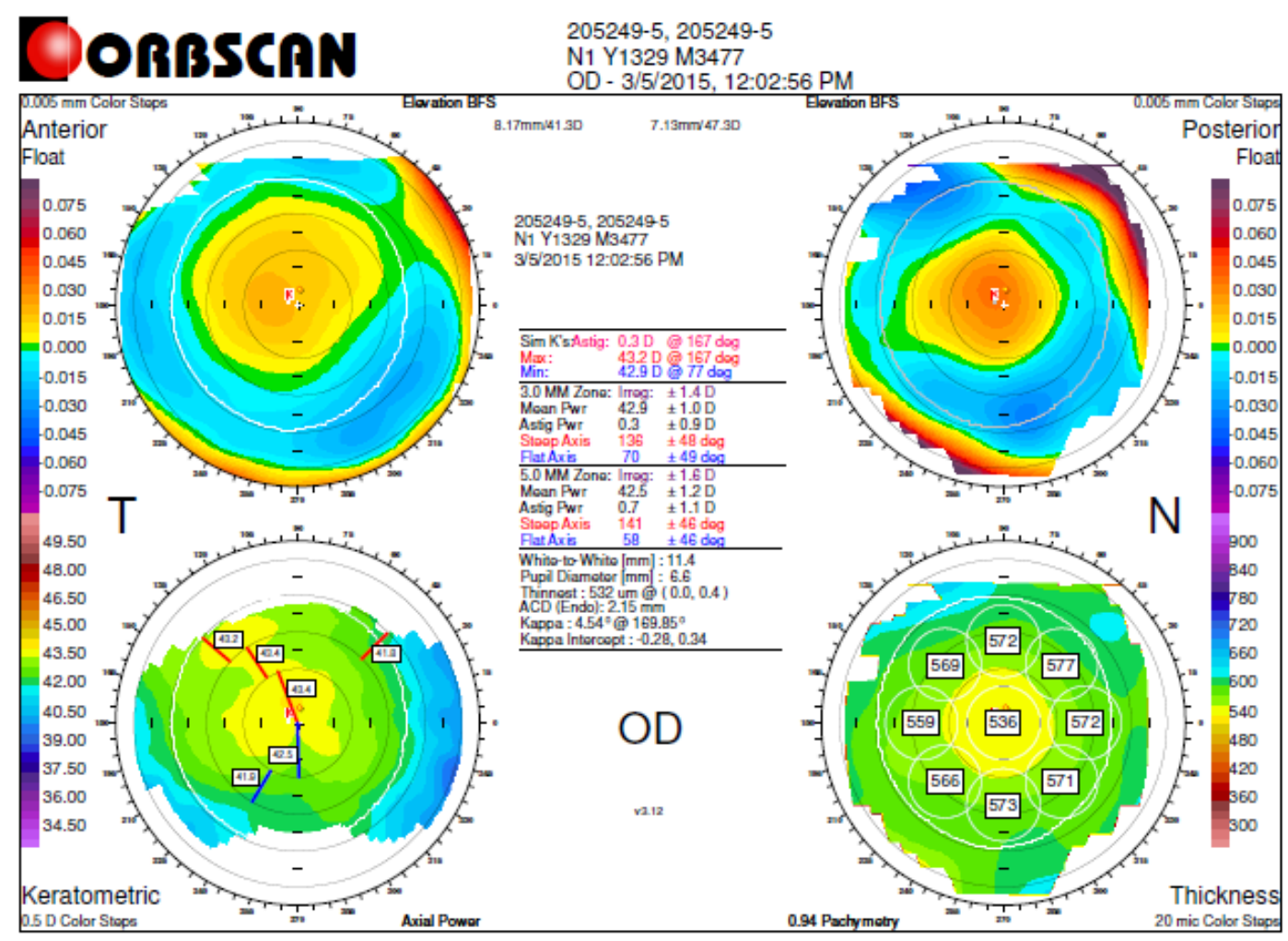

Figure 3. Printout of CCT measurement by scanning slit topography 
However, the ultrasound pachymetry technique remains the gold standard for corneal thickness assessment due to its fast and reliable measurement at low cost. Compared to the ultrasound pachymetry, optical coherence tomography and the scanning slit topography measurements tend to underestimate the corneal thickness in the previous literature (Thomas et al. 2006, Cheng et al. 2008).

\section{Normal CCT values}

CCT varies between different ethnic groups. In Asia, Hong Kong Chinese have the greatest CCT of $574.5 \mu \mathrm{m}$ (Cho \& Lam 1999), followed by $556.2 \mu \mathrm{m}$ of Chinese in the Beijing Eye Study (Zhang et al. 2008), $554 \mu \mathrm{m}$ of Taiwanese Chinese (Chen et al. 2009), 541.2 $\mu \mathrm{m}$ of Singaporean Malays (Wu et al. 2011), $521 \mu \mathrm{m}$ of Japanese (Tomidokoro et al. 2007) and $511.4 \mu \mathrm{m}$ of South Indians (Vijaya et al. 2010). Caucasians in the ocular hypertension treatment study have a mean CCT of $579 \mu \mathrm{m}$ (Brandt et al. 2001), while a mean CCT of $558.5 \mu \mathrm{m}$ is noted in another Caucasian population (Wang et al. 2014). Caucasians usually have thicker corneas than that of Asians. Blacks have thinner corneas of $521 \mu \mathrm{m}$ than other ethnic groups (Aghaian et al. 2004). Hispanics $(550.4 \mu \mathrm{m}$, Wang et al. 2014) have CCT intermediate between Blacks and Caucasians.

Glaucoma is a progressive optic neuropathy with several risk factors including Black race or Hispanic ethnicity. Variation in CCT explained almost 30\% of the increased risk of glaucoma seen among Blacks and Hispanics compared to Caucasians, with adjustment for differences in IOP (Wang et al. 2014). It may be explained by some genetic risk factors for glaucoma co-inherited with CCT (Wang et al. 2014). CCT appears to be an important mediator of the relationship between glaucoma and race. 


\section{CCT and associated ocular}

\section{parameters}

\subsection{CCT and refractive error}

The relationship between CCT and refractive error is controversial across earlier studies. For myopic populations, thinner corneas were reported in 216 young adults with an averaged refractive error of -4.17 diopters (Chang et al. 2001), whereas no correlation with the degree of myopia was found in 714 Singaporean Chinese with a mean refractive error of -5.3 diopters (Fam et al. 2006). For normal populations, a significant correlation between $\mathrm{CCT}$ and refraction was demonstrated in 3021 Japanese (Suzuki et al. 2005). In contrast, other studies failed to reveal a significant correlation between CCT and refraction in 4439 Chinese (Zhang et al. 2008), 500 Taiwanese Chinese (Chen et al. 2009), 652 Singaporean schoolchildren (Tong et al. 2004) and 3239 Singaporean Malays (Su et al. 2009), respectively. It seems that CCT was not correlated with refractive error in most of the studies mentioned above.

\subsection{CCT and corneal curvature}

The relationship between CCT and corneal curvature was investigated in several earlier studies. CCT was positively correlated with corneal curvature in 1976 Americans (Shimmyo et al. 2003), 2868 Japanese (Sawada et al. 2008), 1190 Chinese (Wang et al. 2016) and 4711 Indians (Nangia et al. 2010), respectively. A weak correlation between CCT and corneal curvature was also demonstrated in other studies (Tong et al. 2004, Suzuki et al. 2005). In contrast, no correlation between CCT and corneal curvature was reported in 925 Caucasians (Eyesteinsson et al. 2002). Similar findings were also found in several investigations (Cho \& Lam 1999, Chang et al. 2001, Fam et al. 2006, Chen et al. 2009). Because physiological variation in corneal curvature and index of refraction rarely influence CCT measurements (Olsen \& Ehlers 1984), different methodologies might explain the 
discrepancies in previous studies. The corneal curvature theoretically influences the oblique section of the cornea by using a split prism for optical pachymetry. Investigators attributed their correlation between $\mathrm{CCT}$ and corneal curvature to the specular microscopic device they used (Suzuki et al. 2005).

\subsection{CCT and axial length}

There appears to be no consensus concerning the relationship between CCT and axial length. Significantly thinner CCT was noted in eyeballs with greater axial length (Chang et al 2001, Su et al. 2009). It was proposed that as the surface area of the cornea increased, the corneal stroma became thinner. Reduced corneal thickness could be expected as the eyeball elongated axially. However, no association between CCT and axial length was found in different population studied (Shimmyo \& Orloff 2005, Oliveira et al. 2006, Chen et al. 2009, Nangia et al. 2010). During the development of myopia, the eyeball elongates and the sclera thins, with greater involvement of the posterior segment (Celorio \& Pruett 1991). Although collagen is the main component of the sclera and cornea, glycosaminoglycan and elastin content, hydration and predominant collagen type may vary between them (McBrien \& Gentle 2003). CCT may be unaffected by the scleral thinning that occurs during eyeball elongation.

\section{Conclusion}

There was no consensus with respect to how $\mathrm{CCT}$ varied with refractive error, corneal curvature and axial length. The results may be affected by participants from different ethnic background and clinical setting. In addition, the methods used to measure ocular parameters may not have been uniform in previous studies. For example, ultrasound pachymetry vs. optical methods to measure the $\mathrm{CCT}$ and IOLMaster vs. A-scan to measure axial length were performed in these studies. These differences would confound the results of association between CCT and 
ocular parameters, accounting for the lack of agreement demonstrated in the various studies. In summary, there is no obvious evidence suggesting association between CCT and other ocular parameter. CCT appears to be an independent biological parameter unrelated to refractive error, corneal curvature and axial length. In the future, more studies may determine the physiologic mechanisms by which variation in CCT between individuals and its association with other ocular parameters. 


\section{References}

Aghaian E, Choe JE, Lin S, et al. Central corneal thickness of Caucasians, Chinese, Hispanics, Filipinos, African Americans, and Japanese in a glaucoma clinic. Ophthalmology. 2004; 111(12):2211-2219.

Bourges JL, Alfonsi N, Laliberté JF, et al. Average 3-dimensional models for the comparison of Orbscan II and Pentacam pachymetry maps in normal corneas. Ophthalmology. 2009; 116(11):2064-2071.

Brandt JD, Beiser JA, Kass MA, et al. Central corneal thickness in the ocular hypertension treatment study (OHTS). Ophthalmology. 2001; 108(10):1779-1788.

Celorio JM, Pruett RC. Prevalence of lattice degeneration and its relation to axial length in axial myopia. Am J Ophthalmol. 1991; 111(1):20-23.

Chakrabarti HS, Craig JP, Brahma A, et al. Comparison of corneal thickness measurements using ultrasound and
Orbscan slit-scanning topography in normal and post-LASIK eyes. $\mathbf{J}$ Cataract Refract Surg. 2001; 27(11):1823-1828.

Chang SW, Tsai IL, Hu FR, et al. The cornea in young myopic adults. $\mathrm{Br} \mathrm{J}$ Ophthalmol. 2001; 85(8):961-970.

Chen MJ, Liu YT, Tsai CC, et al. Relationship between central corneal thickness, refractive error, corneal curvature, anterior chamber depth and axial length. J Chin Med Assoc. 2009; 72(3):133-137.

Cheng AC, Rao SK, Lau S, et al. Central corneal thickness measurements by ultrasound, Orbscan II, and Visante OCT after LASIK for myopia. J Refrac Surg. 2008; 24(4):361-365.

Cho P, Lam C. Factors affecting the central corneal thickness of Hong Kong-Chinese. Curr Eye Res. 1999; 18(5):368-374. 
Damji KF, Muni RH, Munger RM.

Influence of corneal variables on accuracy of intraocular pressure measurement. J Glaucoma. 2003; 12(1): 69-80.

Doughty MJ, Zaman ML. Human corneal thickness and its impact on intraocular pressure measures: a review and meta-analysis approach. Surv Ophthalmol. 2000; 44(5):367-408.

Eyesteinsson T, Jonasson F, Sasaki H, et al. Central corneal thickness, radius of the corneal curvature and intraocular pressure in normal subjects using non-contact techniques: Reykjavik Eye Study. Acta Ophthalmol Scand. 2002; 80(1):11-15.

Fam HB, How AC, Baskaran M, Lim KY, et al. Central corneal thickness and its relationship to myopia in Chinese adults. $\mathrm{Br}$ J Ophthalmol. 2006; 90(12):1451-1453.
Funata M, Tokoro T. Scleral change in experimentally myopic monkeys. Graefes Arch Clin Exp Ophthalmol. 1990; 228(2):174-179.

Gordon MO, Beiser JA, Brandt JD, et al. The Ocular Hypertension Treatment Study: baseline factors that predict the onset of primary open-angle glaucoma. Arch Ophthalmol. 2002; 120(2):714-720.

Goss DA, Van Veen HG, Rainey BB, Feng B. Ocular components measured by keratometry, phakometry, and ultrasonography in emmetropic and myopic optometry students. Optom Vis Sci. 1997; 74(7):489-495.

Leske MC, Heijl A, Hyman L, et al. Predictors of long-term progression in the early manifest glaucoma trial. Ophthalmology. 2007; 114(11):1965-1972.

Lin LL, Shih YF, Tsai CB, et al. Epidemiologic study of ocular refraction among schoolchildren in 
Taiwan in 1995. Optom Vis Sci. 1999; 76(5):275-281.

Martin R, de Juan V, Rodríguez G, et al. Measurement of corneal swelling variations without removal of the contact lens during extended wear. Invest Ophthalmol Vis Sci. 2007; 48(7):3043-3050.

Martin R, de Juan V, Rodríguez G, et al. Contact lens-induced corneal peripheral swelling: Orbscan repeatability. Optom Vis Sci. 2009; 86(4):340-349.

McBrien NA, Gentle A. Role of the sclera in the development and pathological complications of myopia. Prog Retin Eye Res. 2003; 22(3):307-338.

Miglior S, Pfeiffer $\mathrm{N}$, Torri $\mathrm{V}$, et al. Predictive factors for open-angle glaucoma among patients with ocular hypertension in the European Glaucoma Prevention Study. Ophthalmology. 2007; 114(1):3-9.

Mitchell P, Hourihan F, Sandbach J, Wang JJ. The relationship between glaucoma and myopia: the Blue Mountains Eye Study.

Ophthalmology. 1999; 106(10):2010-2015.

Nangia V, Jonas JB, Sinha A, et al. Central corneal thickness and its association with ocular and general parameters in Indians: the Central India Eye and Medical Study. Ophthalmology. 2010; 117(7):705-710.

Oliveira C, Tello C, Liebmann J, Ritch R. Central corneal thickness is not related to anterior scleral thickness or axial length. J Glaucom. 2006; 15(3):190-194.

Oliveira CM, Ribeiro C, Franco S. Corneal imaging with slit-scanning and Scheimpflug imaging techniques. Clin Exp Optom. 2011; 94(1):33-42.

Olsen T, Ehlers N. The thickness of the human cornea as determined by a specular method. Acta Ophthalmol (Copenh). 1984; 62(6):859-871. 
Rio-Cristobal A, Martin R. Corneal assessment technologies: current status. Surv Ophthalmol. 2014; 59(6):599-614.

Sawada A, Tomidokoro A, Araie M, et al. Refractive errors in an elderly Japanese population: the Tajimi study. Ophthalmology. 2008; 115(2):363-370.

Shimmyo M, Orloff PN. Cornea thickness and axial length. Am J Ophthalmol. 2005; 139(3):553-554.

Shimmyo M, Ross AJ, Moy AJ, Mostafavi B. Intraocular pressure, Goldmann applanation tension, cornea thickness, and corneal curvature in Caucasians, Asians, Hispanics and African Americans. Am J Ophthalmol. 2003; 136(4):603-611.

Singh RP, Goldberg I, Graham SL, et al. Central corneal thickness, tonometry, and ocular dimensions in glaucoma and ocular hypertension. J Glaucoma. 2001; 10(3):206-210.
Su DH, Wong TY, Foster PJ, et al. Central corneal thickness and its associations with ocular and systemic factors: the Singapore Malay Eye Study. Am J Ophthalmol. 2009; 147(4):709-716.

Suzuki S, Suzuki Y, Iwase A, et al. Corneal thickness in an ophthalmologically normal Japanese population. Ophthalmology. 2005; 112(8):1327-1336.

Thomas J, Wang J, Rollons AM, et al. Comparison of corneal thickness measured with optical coherence tomography, ultrasonic pachymetry, and a scanning slit method. J Refrac Surg. 2006; 22(7):671-678.

Tomidokoro A, Araie M, Iwase A. Corneal Thickness and Relating Factors in a Population-Based Study in Japan: The Tajimi Study. Am J Ophthalmol. 2007; 144(1):152-154.

Tong L, Saw SM, Siak JK, et al. Corneal thickness determination and correlates in Singaporean 
schoolchildren. Invest Ophthalmol

Vis Sci. 2004; 45(11):4004-4009.

Vijaya L, George R, Arvind $\mathrm{H}$, et al. Central corneal thickness in adult south Indians: the Chennai Glaucoma Study. Ophthalmology. 2010; 117(4):700-704.

Wang Q, Liu W, Wu Y, et al. corneal thickness and its relationship to ocular parameters in young adult myopic eyes. Clin Exp Optom. 2016 Oct 18 .

Wang SY, Melles R, Lin SC. The impact of central corneal thickness on the risk for glaucoma in a large multiethnic population. J Glaucoma. 2014; 23(9):606-612.

Wu RY, Zheng YF, Wong TY, et al. Relationship of central corneal thickness with optic disc parameters: the Singapore Malay Eye Study. Invest Ophthalmol Vis Sci. 2011; 52(3):1320-1324.

Zhang H, Xu L, Chen C, Jonas JB. Central corneal thickness in adult Chinese. Association with ocular and general parameters. The Beijing Eye Study. Graefes Arch Clin Exp Ophthalmol. 2008; 246(4):587-592. 